\title{
Trabajo social familiar: la dimensión intercultural como fuerza de las familias para el cambio
}

\section{Alejandra Santana López*}

Lilian Sanhueza Díaz ${ }^{*}$

\section{RESUMEN}

La intervención familiar, desde Trabajo Social, resulta una tarea compleja, considerando las actuales características de la familia contemporánea. Desde ahí, resulta desafiante aproximarse a ella, desde lo cultural - intercultural, y validar esta dimensión como una fuerza que potencia la intervención, reconociendo el protagonismo de las familias en sus propias transformaciones.

Palabras clave: Trabajo social familiar / Interculturalidad / Familia mapuche / Perspectiva de las fuerzas.

\section{Family social work: the intercultural dimension as the driving force of the families for the change}

ABSTRACT

Family intervention, from Social Work, turns out to be a complex task, considering the current characteristics of the contemporary family. From there, it turns out to be novel and challenging to come closer it, from the cultural - crosscultural thing, and to validate this dimension as a strength hat promotes the intervention, recognizing the protagonism of the families in theirs own transformations.

Key words: Family social work, cultural - cross, Mapuche family, strengths perspective.

* Chilena, Trabajadora Social. Magíster en Psicología (PUC). Docente Escuela de Trabajo Social de la Universidad Santo Tomas. Correo electrónico: asantana@ santotomas.cl

** Chilena, Trabajadora Social. Docente Escuela de Trabajo Social de la Universidad Católica de Temuco. Correo electrónico: 1sanhueza@uct.cl 


\section{Antecedentes}

La familia contemporánea expresa en sí misma las múltiples tensiones, contradicciones y diversidades de un contexto complejo que al parecer, permea inevitablemente las estructuras sociales en las cuales estamos insertos e interrelacionados. Así, más que hablar de la familia contemporánea sería prudente hablar de las múltiples familias contemporáneas, ya que al mirar con detención el carácter que ha tomado ésta en la última década, resulta difícil describirla como una estructura única, homogénea o estática, ya que al considerar las dimensiones socio-políticas, socio-culturales y socio-económicas, propias de un contexto de modernización (Aylwin, Solar2003:17), obtenemos como resultado diversas tipologías familiares e imaginarios sociales asociados a ellas. (Güell, 2004; González, 2000; PNUD,2002, CEPAL,2004).

Desde aquí, quienes se planteen trabajar con familias, pretendiendo generar cambios en su interior, como es el caso de muchos Trabajadores Sociales, debieran recoger esta complejidad, comprenderla y potenciarla como un recurso para la intervención.

Al ubicar a la familia en una matriz eco-sistémica (Bronfenbrenner, 1987), se pueden reconocer múltiples ambientes que la afectan y que a su vez son influidos por las familias. Habitualmente, cuando intencionamos cambios en su interior, privilegiamos el foco en los ambientes inmediatos y más cercanos a la estructura familiar. Sin embargo, hay propiedades que se ubican en lo macro-sistémico, que contienen el soporte cultural, las creencias y valores más arraigados de las familias contemporáneas.

En el nivel macro se reconocen elementos culturales propios de una determinada sociedad, en este caso la chilena, pero también contiene la propia construcción cultural de cada familia. Así, vemos que "cada familia posee en su bagaje elementos culturales propios de su linaje o clan familiar, y otros de su comunidad, pueblo o nación de pertenencia. El compartir una misma cultura refuerza el sentimiento de cohesión y de pertenencia de una familia determinada" (Barudy, 2001:44). Así, una serie de representaciones y discursos sociales sirven de referencia a los miembros de una familia como imágenes guías y modelos de comportamiento en lo que concierne a los roles de cada miembro, sus conductas y la forma de relacionarse. 
Detener la mirada profesional en lo cultural de las familias, es relevante si lo que buscamos es provocar cambios en ellas que provengan de sus más arraigadas convicciones, que sean sostenibles en el tiempo y que favorezcan el mejoramiento de su calidad de vida, de su bienestar psicosocial y de sus niveles de desarrollo humano. De esta manera, la dimensión cultural constituiría un aliado en la generación de cambios desde la esencia de la estructura familiar.

Particularmente, en el espacio que nos permite esta reflexión, quisiéramos detenernos en un elemento que nutre la complejidad de las familias contemporáneas, propio de la dimensión socio-cultural: la interculturalidad. Se entiende ésta como "la acción comunicativa que se produce entre dos o más grupos humanos de diferente cultura" (Tomas, 2000:145). Para articular el análisis, tomaremos como un ejemplo cercano, las intervenciones familiares realizadas con familias mapuches en la IX región, donde está a la base la acción comunicativa entre familias mapuches y profesionales, instituciones y políticas no-mapuches.

Desde ahí, es ineludible referirnos a la intervención familiar desde Trabajo Social, que permanentemente ha ofrecido novedosos sitios desde donde acompañar a las familias en sus caminos de cambio.

En esta ocasión optamos por abordar el análisis desde la perspectiva de las fuerzas. Esta releva "los recursos de las personas y de sus ambientes, más que sus patologías y problemas, (siendo éstos) el foco central del proceso de ayuda a la familia" (Weick y Saleeby, 1995 en Aylwin y Solar, 2003:160).

De esta forma, considerando la interculturalidad y la intervención familiar desde la perspectiva de las fuerzas, surgen algunos cuestionamientos, que pueden ser compartidos con quienes día a día enfrentan los desafíos de crear y recrear intervenciones efectivas, ágiles y pertinentes en contextos de cambio que no siempre favorecen estos procesos: ¿Qué lugar ocupa lo intercultural en el diseño de las políticas sociales actuales que se dirigen a las familias?; ¿Cómo se traduce esto en las líneas programáticas de trabajo con familias? ¿De qué manera el trabajo social recoge lo intercultural como una fuerza presente en las familias y lo incorpora explícitamente en las intervenciones?; ¿Qué ubicación toma el trabajo social en esta relación intercultural? 


\section{La Interculturalidad como una dimensión de la Intervención Familiar}

Para el abordaje de este tema, se consideran tres aspectos centrales en el trabajo con familias desde una mirada intercultural. Estos corresponden a la identidad y familia mapuche; la familia mapuche contemporánea y el trabajo social familiar; y el poder en el trabajo social con familias.

\section{a) Identidad y familia mapuche}

La dimensión intercultural desde los valores que sustenta el trabajo social familiar, entre ellos, el respeto por el otro -el otro como otredad, no como otro yo- y la autodeterminación (AIETS y FITS 2004:3), debiera entenderse como el diálogo entre dos culturas, que se encuentran en una relación simétrica (Zabala, 2004:16).

Cuando nos referimos a la relación entre el Estado chileno y las familias mapuches, por ejemplo, es insoslayable reconocer que esta relación históricamente ha presentado fuertes elementos de asimetría, basados en la dominación y/o la integración forzada, desconociendo los elementos distintivos propios de la identidad cultural de las familias mapuches. "Las relaciones interculturales entre mapuches y chilenos han estado determinadas y mediadas por la estructura de poder de las fuerzas dominantes y se vinculan a dinámicas ideológicas y de políticas económicas, históricas y circunstanciales" (Millaman, 2004:40). Desde ahí que las instituciones que operacionalizan las políticas sociales, inevitablemente contarán con el peso de la relación histórica entre Estado chileno y pueblo mapuche.

Como una forma de rescatar la cultura en el contexto de la integración a la sociedad global, surge la noción de identidad cultural. La identidad "es una manera de movilizar algunas formas simbólicas presentes en la cultura para construir un relato sobre el sí mismo tomado como objeto. Mientras la cultura es la estructura general de significados incorporados en las formas simbólicas en contextos precisos, la identidad moviliza sólo algunos de estos significados para contar la historia del sí mismo" (Larraín, 2007:117)

Cada familia tiene un repertorio de narraciones que hablan de la historia familiar, la identidad, los mitos, los ritos y, en definitiva, aquellos dispositivos que le permiten diferenciarse de su entorno. 
Estos corresponden a la estructura de la familia como sistema complejo, y son los que le facilitan construir un relato de sí misma, a partir del cual relacionarse con su entorno.

La identidad de la familia mapuche se va configurando en base a la experiencia individual y colectiva de acuerdo con los distintos roles y posiciones sociales que adquieren en su entorno en estrecha articulación con la socialización desde el linaje, a través de pautas transgeneracionales que transmiten los valores propios de la cultura.

Desde un punto de vista intercultural, una aproximación al concepto de familia sería concibiéndola como "una forma de organización social, que establece dinámicas de relación consideradas legítimas en un contexto sociocultural determinado" (Morandé, 1994:24). Para Morandé la familia combina tres tipos de relaciones: la filiación, la consanguinidad y la alianza conyugal. Señala igualmente, que "la familia es una de las instituciones más importantes de la oralidad, que se da en la presencia cara a cara y que reconoce en el rostro humano "enfrente" no sólo un objeto, sino un espíritu encarnado que se pregunta por su dignidad y por su vocación" (1994:24)

La familia como organización social contribuye a la formación de la identidad personal, ante todo porque es el lugar de la pertenencia, simbolizada por el apellido, que alude a una realidad mayor a la que pertenecemos pero que nos trasciende, y además por el nombre, que nos aporta una especificidad individual no intercambiable. "Esta experiencia de nombrar a otros y de ser nombrados por ellos, constituye el núcleo de la cultura oral y está vinculada de manera estrecha a la familia (Morandé, 1994:26).

\section{b) Familia mapuche contemporánea y el trabajo social familiar}

La familia "ha sido el núcleo histórico de la sociedad mapuche" (Bengoa, 1996:7), es además "la organización básica para que el individuo mapuche integre la lengua y el Admapu', es la institución de mayor incidencia en la socialización, porque se hace en estrecho vínculo con una diversidad de generaciones: abuelos, padres, tíos,

1 El Admapu es un concepto mapuche que alude a las normas para vivir en armonía dentro de su entorno social y natural. 
hermanos, propiciado por el ambiente de la transmisión y la recreación de la cultura" (1996:7). Desde ahí, puede asumirse, que cualquier intervención de carácter familiar en que se le legitime como actor social, impactará directamente en el fortalecimiento de las dimensiones familiares-comunitarias.

En la interacción cotidiana que los trabajadores sociales realizan con familias mapuches, aparecen con fuerza de parte de éstas, expectativas relacionadas con la necesidad de integración a la sociedad chilena, accediendo a los recursos y beneficios que como ciudadanos chilenos poseen. No obstante, paralelo a ello, surge la inquietud por resguardar elementos identitarios culturales, tales como, la vida en comunidad, la estrecha relación con la tierra, la complementariedad en el equilibrio del hombre con su entorno. En definitiva, todos aquellos aspectos que componen el kimün o sabiduría mapuche (Manquenahuel, 2006).

Estos elementos identitarios son aún más significativos en familias rurales que se mantienen viviendo en comunidad, con validación de autoridades tradicionales y mantenimiento de ceremoniales propios de la cultura mapuche (Manquenahuel, 2006). La familia mapuche no tiene una identidad única, pues combina elementos, comparte estilos de vida y prácticas sociales con el resto de las familias chilenas, lo que las hace formar parte simultáneamente de una identidad nacional, además de la identidad étnica.

Desde las intervenciones sociales es posible invisibilizar los elementos identitarios, por ejemplo, en programas orientados a la protección de los derechos infanto-adolescentes, orientados por la Convención Internacional de los Derechos del Niño (CIDN). Ésta, se puede entender como dispositivo de modernidad en términos de que, como plataforma legal y sociocultural, viene a establecer un estilo de relación democrático entre el mundo adulto y la infancia; y en este sentido, genera una serie de complejidades para la intervención.

En familias que habitan en sectores rurales o que han migrado a la ciudad sólo en la última generación, manteniendo fuertes vínculos con la vida rural, es posible constatar que muchos de los actuales padres, presentan historias de vida muy distintas a las que actualmente la CIDN pretende instaurar. Muchos de ellos enyugaban bueyes a los 7 u 8 años y las madres ya sabían hacer pan a esa edad, lo 
cual les proporcionaba un fuerte sentimiento de reconocimiento y estima en la familia extensa y la comunidad. Hoy en día, atendiendo las orientaciones de la CIDN, ello es cuestionable. Muchos de los niños y niñas pertenecientes a familias mapuche rurales, apoyan en las labores de la huerta, cuidado de las aves de corral, ganado, cosecha, elaboración de tortillas para la venta y en ese proceso van adquiriendo un espacio y validez dentro de la dinámica de la familia campesina. Así, esta dinámica constituye un "modo de socialización endocultural" (Samaniego, 2004:114).

\section{C) El poder en el Trabajo Social con familias}

El trabajo social con familias en general y con familias mapuches en particular, se desarrolla dentro de un metacontexto institucional el cual, de acuerdo a Lamas corresponde a la "construcción social de las instituciones" (Lamas, 1997:92), en la medida que se conforma un imaginario social acerca de lo que se espera de cada organización a partir de una serie de símbolos y códigos compartidos.

De acuerdo a Castillo (1995) dentro de las instituciones se encuentran las llamadas "organizaciones de servicios sociales", las que pueden ser concebidas como un todo compuesto por los elementos organizacionales, relaciones de poder y lineamientos políticos que en una interacción recursiva y permanente con los sujetos que operan en dicho sistema se autoorganiza y autorregula. Desde esta perspectiva, muchos profesionales trabajadores sociales se han incorporado en metacontextos institucionales que no favorecen una perspectiva intercultural, ya sea porque la política pública o social que operaciona no lo explicita, o porque la naturaleza del metacontexto no da cabida a esta relación.

Siguiendo a Foucault (1985) en la lógica de que el poder es un fenómeno relacional, recíproco y regulado, que no existe en general, sino que se da en cierto dominio, en una situación concreta, los profesionales al formar parte del complejo sistema de organización de servicios sociales, tienen influencia sobre él al detentar ciertas cuotas de poder. Al mismo tiempo que las familias mapuches ejercitan el poder a través de la resistencia -expresada de distintas manerasa procesos de intervención más invasivos, rígidos que no reconocen la otredad presente en ellos, relacionándose asimetrícamente y de forma mediatizada por una metodología en ocasiones inflexible y 
con un fuerte componente de control social, basada en enfoques positivistas y tecnocráticos.

\section{La Intervención Familiar desde la Perspectiva de las Fuerzas}

\section{a) Intervención familiar desde Trabajo Social}

En un intento de construir una noción de intervención social de índole familiar que nos interprete, la denominamos como aquella acción social -contextualizada en toda su complejidad- que se centra directa o indirectamente en las relaciones familiares y en las relaciones que se generan entre las familias y sus entornos o ambientes, aspirando permanentemente alcanzar -desde sí misma-transformaciones a favor de su desarrollo y bienestar, en un sentido amplio.

Para Aylwin y Solar, lo nuevo del trabajo social familiar podría resumirse como "una refocalización en la familia que, al fundamentarse en nuevos aportes teóricos, permite un abordaje de su objeto en términos de totalidad de una forma diferente a la tradicional. Esta nueva modalidad exige el desarrollo de una perspectiva interaccional, un mayor énfasis en las fortalezas de las familias y una participación activa de la familia con el trabajador social en el uso de una mayor variedad de estrategias y técnicas de intervención. Al mismo tiempo requiere el desarrollo de un enfoque familiar que va más allá de la intervención directa con las familias y que se proyecte hacia las políticas sociales y hacia la sociedad global, en base a los conocimientos generados por la profesión a través de la práctica y la investigación" (Aylwin y Solar, 2003:88).

Así desde un trabajo social familiar, que privilegia lo interaccional y el protagonismo de las familias, el accionar de los trabajadores sociales con familias mapuches, bajo una lógica intercultural, donde lo intercultural no es sólo un adjetivo, sino un objetivo a lograr, en tanto relación de respeto activo y reconocimiento del otro, se podría plantear como un tipo de acción social intencionada, realizada por trabajadores sociales con la finalidad de transformar una situación de malestar social, significada como tal por personas, grupos y comunidades, a través de un proceso intersubjetivo que se desarrolla mediante la interacción cotidiana en el mundo de la vida y que interpela al profesional a actuar, en un metacontexto institucional. 
Esta acción social profesional es eminentemente comunicativa e involucra los niveles cognitivo, emocional y pragmático en la relación con las otras personas, basada en el reconocimiento de los otros y en el compromiso ético que conlleva dicho reconocimiento.

En este encuentro con el otro, el trabajador social va desarrollando, a través de un proceso dialógico, un reconocimiento de lo distinto, que muchas veces se constituye en aquello que en las familias mapuches genera identidad, cohesión y que es la fuerza que sostiene al grupo humano.

\section{b) Perspectiva de las fuerzas}

La perspectiva de las fuerzas es una posibilidad de aproximarse a la realidad familiar. Ésta "propone que los recursos de las personas y de sus ambientes, más que sus patologías y problemas, debieran ser el foco central del proceso de ayuda a la familia" (Aylwin y Solar, 2003: 160). Encausando la ayuda en "la identificación, uso y aumento de las fuerzas y recursos en la persona y medio ambiente" (Sullivan, 1992 en Aylwin y Solar, 2003: 160), de tal forma de valorar y trabajar intencionadamente las potencialidades de las familias.

Las personas interpretan la realidad en la que viven y seleccionan algunos acontecimientos que pasan a formar parte de su experiencia. A los acontecimientos elegidos se les asignan una serie de significados y todos ellos forman parte del relato que da sentido y propositividad a su vida.

En la relación profesional-familia es fundamental, trabajar con los recursos de las personas, lo que implica primero, creer en esos recursos. Las familias en situación de extrema pobreza y vulnerabilidad social, han logrado sobrevivir gracias a una serie de estrategias implementadas para ello; más allá de una mirada normativa, lo importante es re-conocer los recursos existentes en ellas, los que hasta ahora les han permitido sobrevivir y a partir de éstos, co-construir en conjunto estrategias que resguarden el bienestar de todos los miembros del grupo familiar.

Cuando la familia construye un relato de sí misma, basada en carencias, déficit o en lo que White y Epston (1980) denominan "historia saturada de problemas", generalmente los actores sociales refuerzan ese relato, ya sea a través de la victimización ("pobre familia") 
o del abuso de poder ("lo que ustedes tienen que hacer es..."), olvidando la importancia de otorgar, a través de la relación profesional, nuevas posibilidades que permitan a la familia una forma distinta de concebirse a sí misma.

La práctica con familias basada en el empoderamiento asume que el poder de la persona se logra cuando escoge alternativas que le dan mayor control sobre sus situaciones problemáticas y, por ende, sobre su propia vida. Sin embargo, la práctica basada en el empoderamiento también asume la justicia social, reconociendo que el empoderamiento y la autodeterminación dependen no sólo de que las personas escojan alternativas, sino también de que tengan acceso a alternativas que escoger"(Aylwin y Solar, 2003:163).

Es posible reconocer modelos explicativos y de intervención social que reflejen con mayor nitidez la noción de fuerza en las personas, familias y ambientes comunitarios, entre ellos, el Modelo de Competencias y el Modelo de factores protectores familiares.

\section{Modelos de Competencias}

En coherencia con los postulados de la perspectiva de las Fuerzas, es posible ubicar en esta línea, al Modelo de Competencias. Este nace bajo el alero de la salud, siendo incorporado al quehacer psicosocial, desde la salud mental, la psiquiatría y la psicología comunitaria. Reconoce la importancia de considerar las variables ambientales en la conceptualización de los problemas de salud mental, pero centrándose en los recursos de los individuos y los ambientes. Desde ahí, las intervenciones se refieren a crear y promover condiciones que faciliten el desarrollo de los propios recursos y de las potencialidades en la solución de problemas relacionados con el bienestar psicosocial (Arón, 2001: 43).

El supuesto básico con que opera este modelo es el de confianza en los recursos del individuo y la comunidad para resolver sus propios problemas. Desde ahí que el papel de los profesionales será contribuir a descubrir sus propios recursos, a activarlos y a recobrar su confianza en ellos. Así, las intervenciones deberán apuntar a fortalecer la confianza en los propios recursos para enfrentar distintas situaciones, ayudando a activar las fuentes de apoyo, permitiendo encontrar sus propios caminos para resolver las situaciones que les aquejan. 
Los modelos de competencias promueven relaciones de respeto y cooperación entre los profesionales y las personas; manejan un supuesto de confianza en los recursos de los individuos y las comunidades para resolver sus propios problemas; enfatizan las intervenciones preventivas, y establecen relaciones de fortalecimiento y asociación con las personas y con los miembros de otros equipos de trabajo.

En esta lógica, una experiencia interesante es la que se ha llevado a cabo en el ámbito de salud intercultural en la atención de parto, desde el Hospital de Iquique con mujeres aymarás. Estas, tradicionalmente daban a luz "en posición vertical, sentadas o de pie, y permanecían muy abrigadas para no enfermarse, ya que existe una lógica de equilibrio calor-frío; donde este último es concebido como un vehículo que transmite males, sobre todo en situaciones de vulnerabilidad. Actualmente este Hospital cuenta con una sala especialmente adornada con motivos propios de su cultura para que ellas den a luz de la forma que más les acomode (de pie, acostadas sobre una cama, sentadas en el piso o en una mesa ginecológica). El lugar cuenta además, con calefacción y pueden permanecer arropadas con frazadas o colchas tejidas, bebiendo sus infusiones y acompañadas por familiares, su partera y la matrona del hospital, lo que evidentemente favorece los vínculos familiares en el contexto de la propia cosmovisión e identidad cultural" (González, 2003).

\section{Factores Protectores de la Familia}

Otro modelo que puede desprenderse de la perspectiva de las fuerzas, son los Factores Protectores Familiares. Estos, de acuerdo a Hidalgo y Carrasco (2002) aparecen como contraparte de los factores de riesgo estudiados desde este modelo, principalmente en el área de la salud familiar.

"Los factores protectores son aquellos que reducen la probabilidad de emitir conductas de riesgo o de tener consecuencias negativas cuando se involucran en ellas (...) éstos pueden considerarse como los recursos $(. .$.$) que tiene una familia para enfrentar su desarrollo$ y eventos vitales. Son características, rasgos, habilidades, competencias, medios, tanto de los individuos de una familia, de la familia como unidad y de su comunidad" (Hidalgo y Carrasco, 2002:62). De esta forma, para cada una de estas instancias, se podrían reconocer los siguientes recursos: 
- A nivel personal: Inteligencia, comprensión, conocimientos, habilidades adquiridas con la educación, rasgos de personalidad, sensación de control de la propia vida y la autoestima.

- A nivel familiar: Asociados al funcionamiento familiar, cohesión y flexibilidad, incluyendo aspectos como confianza, aprecio, soporte emocional y respeto por la individualidad, habilidades de comunicación, capacidad para usar la red social, entre otros. Hay que recordar que la familia mapuche es también la comunidad y eso es un factor protector, ya que la red primaria se amplía y por tanto los vínculos son más emocionales que instrumentales.

- A nivel comunitario: Características, competencias de personas, grupos e instituciones con las cuales la familia puede contar o acceder para satisfacer sus necesidades. Cabe señalar que uno de los factores protectores más relevantes es el apoyo social, pudiendo obtenerse de cualquier miembro de la red social.

Desde una perspectiva intercultural, los factores protectores de la familia mapuche están íntimamente relacionados con su identidad y con una relación con el entorno que reconozca dicha identidad.

\section{Reflexiones Finales}

Luego este recorrido podemos afirmar que considerar activamente la dimensión cultural, y particularmente lo intercultural en el trabajo con familias, puede significar abordarlo desde su valía como fuerza, desde el reconocimiento de una serie de competencias familiares asociadas a ello, hasta la identificación de factores protectores desplegados para las familias y sus entornos, entre otras posibilidades.

Hasta ahora, nos hemos referido a lo que le ocurre a las familias en una situación intercultural, donde esta dimensión tiene cariz de fuerza en las intervenciones, sin embargo, también se puede señalar que el análisis desde el enfoque familiar en sí mismo conlleva mirar las potencialidades, fuerzas, y propiedades de este grupo social. Reconociendo las competencias instaladas en la forma de funcionar, su acumulado histórico y la herencia intergeneracional que favorece la transmisión de ritos, creencias y formas de ver el mundo, y su forma de situarse en los contextos socio-comunitarios en que se desarrolla. 
Desde ahí, hemos esbozado algunas ideas relativas a la intervención familiar desde la mirada intercultural, la finalidad de ésta y las condicionantes contextuales que la determinan.

El desarrollo de la intervención que declare reconocer las variables interculturales, necesariamente será un proceso que medie un cambio o transformación, y que en este ejercicio se considere:

- Una noción de familia lo suficiente amplia y flexible que de cabida a la representación que otra cultura hace de la estructura familiar.

- La construcción de una relación culturalmente simétrica, que desde ahí, valide al otro como un otro legítimo.

- Favorecer una actitud de respeto genuino por los elementos propios de la identidad cultural que surjan en el desarrollo de la intervención.

- Intencionar en la intervención con familia en una relación intercultural, el énfasis en las fortalezas familiares, siendo capaz de visualizarlas y activarlas como motor de cambio.

- Confiar en los recursos de las personas, familias y entornos en la relación intercultural, reflejándose en una efectiva movilización de aspectos constitutivos de la identidad cultural en pro de los cambios que favorezcan a las familias en un sentido integral.

En relación al fin de la intervención con familias desde la lógica intercultural, que es alcanzar una transformación en una situación dada y compleja, sería pertinente articular la idea de cambio con las variables culturales, otorgando un sentido y significado particular a éste, desde los referentes culturales valorados por las familias. Asegurando en parte, su instalación, pertinencia e impacto.

La intervención con familia, al igual que otras intervenciones sociales, está contextualizada. Parte de la contextualización, está determinada por las sociedades de pertenencia de las familias, los metacontextos de cambio en que se desarrollan las intervenciones y las relaciones profesionales generadas. Desde ahí que para alcanzar una intervención familiar intercultural, se hace necesaria la sintonía con estos niveles, con el fin de garantizar la voluntad socio-política que respalde la perspectiva intercultural en los marcos institucio- 
nales. De lo contrario, sólo responderá a esfuerzos individuales de aquellos profesionales más sensibilizados con esta perspectiva.

De esta forma, se evidencian desafíos asociados a las lógicas institucionales que incluyan la mirada intercultural, no sólo acotado a lo étnico, sino a otras expresiones culturales que coexisten en nuestra sociedad.

Por su parte, a los profesionales nos desafía a la revisión de nuestras capacidades para incorporar la mirada intercultural de manera integradora; a desarrollar habilidades y competencias profesionales y de equipo que soporten esta tarea; en definitiva, a ser interlocutores válidos en la relación intercultural, facilitadores a la hora de descubrir los recursos familiares, activando y articulando adecuadamente la red de apoyo social de sus entornos.

Dejamos abierta la invitación a seguir pensando nuevos aportes y perspectivas que enriquezcan la comprensión de lo intercultural como fuerza de la intervención con familias.

\section{Referencias bibliográficas}

AIETS \& FITS. (2004). Documento de Ética. Propuesta Final Asamblea. Recuperado el 20 de Agosto. De http://www.cnaass. tie.cl

ARON, M. (2001). Violencia en la Familia. Programa de intervención en red: la experiencia de San Bernardo. Santiago, Chile: Galdoc.

AYLWIN, N. E SOLAR, M. (2003).

Trabajo Social Familiar. Santiago, Chile: Ediciones Universidad Católica de Chile.

BARUDY, J. (2001). Maltrato infantil. Ecología social: prevención y reparación. Santiago, Chile: Galdoc.

BENGOA, J. (1996). Historia del Pueblo Mapuche (Siglo XIX y XX). Santiago, Chile: Ediciones Sur Colección Estudios Históricos.

BRONFENBRENNER, U. (1987).

La Ecología del Desarrollo Humano. Barcelona: Paidós. 
CASTILLO, F. (1997). El Profesional en las Organizaciones de Servicios Sociales. En Coletti E Linares (1997). La intervención sistémica en los servicios sociales ante la familia multiproblemática. La experiencia de Ciutat Vella. Buenos Aires: Paidós Terapia Familiar.

COMISIÓN ECONÓMICA PARA AMÉRICA LATINA Y EL CARIBE (2004). Cambio de las familias en el marco de las transformaciones globales: necesidad de políticas públicas eficaces. Serie Seminarios y Conferencias, $\mathrm{n}^{\circ} 42$. Santiago, Chile: AUTOR.

FOUCAUlT, M. (1985). Microfísica del Poder. RJ: Graal.

GONZÁLEZ, A. (2003). Mujeres indígenas tienen derecho a un parto integrador. Recuperado el 15 de Septiembre. De http:// www.mujereshoy.com

GONZÁLEZ, J. (2000). Tendencias de la dinámica demográfica en la familia. En: Revista Universitaria, 69.

GÜELL, P. (2004). Familia y Modernización en Chile. En línea en $<$ http://www.pnud.cl>

HIDALGO, C. y CARRASCO, E. (2002).

Salud Familiar: un modelo de atención integral en atención primaria. Santiago, Chile: Ediciones Universidad Católica de Chile.

LAMAS, C. (1997). Los Primeros Contactos. En Coletti \& Linares (1997). La intervención sistémica en los servicios sociales ante la familia multiproblemática. La experiencia de Ciutat Vella. Buenos Aires: Paidós.

LARRAÍN, J. (2000). Identidad y Modernidad en América latina. México D.F: Océano.

MANQUENAHUEL, P. (2007).

Apuntes Taller "La cultura mapuche". Universidad Católica de Temuco, Escuela de Trabajo Social.

MILLAMÁN, R. (2004). Relaciones Interraciales e Interétnicas de Mapuches con no Mapuches. En Samaniego $\varepsilon$ Garbarini (2004). Rostros y Fronteras de la Identidad. Temuco: Ediciones Universidad Católica de Temuco.

MORANDÉ, P. (1994). Persona, matrimonio y familia. Santiago, Chile: Ediciones Universidad Católica de Chile. 
PROGRAMA DE LAS NACIONES UNIDAS PARA EL DESARROLLO (2002).

Informe Desarrollo Humano en Chile. Nosotros los chilenos: un desafío cultural. Santiago, Chile: AUTOR.

SAMANIEGO, M. Y GARBARINI, C. (2004).

Rostros y Fronteras de la Identidad. Temuco: Ediciones Universidad Católica de Temuco.

TOMAS, R. (2000). Comunicación Intercultural. Fundamentos y Sugerencias. México: CONACULTA.

WHITE, M. Y EPSTON, E. (1980).

Medios narrativos para fines terapéuticos. Barceloa: Paidós.

ZABALA, J. (2004). La interculturalidad desde una perspectiva etnohistórica en el contexto mapuche. En Samaniego, M. E Garbarini, C. (2004). Rostros y Fronteras de la Identidad. Temuco: Ediciones Universidad Católica de Temuco. 